\title{
Trece razones para una puesta al día en la moral sexual católica
}

\author{
Cristián Barría Iroumé, \\ Universidad Alberto Hurtado, \\ Santiago de Chile
}

Desde hace más de cuarenta años la jerarquía de la Iglesia católica insiste en rechazar moralmente el uso de técnicas que la enorme mayoría de personas considera beneficiosas para la humanidad, como la píldora anticonceptiva, los métodos de fertilización asistida, el uso del condón como medio para evitar el embarazo y la prevención de una enfermedad como el sida. En otro plano, la enseñanza oficial cuestiona severamente a todos los divorciados en segundo matrimonio y los excluye de la comunión.

Estas posturas morales se han vuelto incomprensibles para el pensamiento actual y progresivamente han aislado a la Iglesia de la opinión pública en los temas de sexualidad, llevándola a un serio conflicto con la cultura moderna.

Fundamentamos aquí las razones por las cuales muchos fieles de hoy pensamos que el magisterio de la Iglesia debe abrirse a un diálogo comunitario sobre estos temas, con el fin de ponerse al día y renovarse.

En la renovación que ha hecho el pensamiento cristiano en la modernidad, la moral sexual ha quedado rezagada. El último concilio inició una profunda renovación en muchos niveles, reconociendo que nuestra era se caracteriza por "cambios rápidos y profundos", por cambios "en el modo de pensar y reaccionar ante las cosas".

Las condiciones de vida del hombre moderno han cambiado tan radicalmente en sus aspectos social y cultural, que hoy se puede hablar de una nueva era de la historia. El género humano pasa así de una concepción más bien estática del orden cósmico, a otra más dinámica y evolutiva: de donde surge una gran complejidad de problemas que está desafiando a la búsqueda de nuevos análisis y nuevas síntesis. 
Reconoció el concilio que "esta metamorfosis, como sucede en toda crisis de crecimiento, trae consigo no ligeras dificultades" (Gaudium et spes 4, 54, 5).

Pues bien, desde hace 50 años, en el área de la sexualidad se están gestando nuevos análisis y nuevas síntesis que aún no han sido comprendidos ni acogidos en la doctrina oficial. Este desencuentro constituye una crisis de crecimiento aún no resuelta. Describimos ahora varias formas en las que se expresa esta crisis. En ellas se repite un desfase entre lo nuevo y la enseñanza clásica de la jerarquía, lo que nos debe interpelar.

\section{Los laicos católicos no han recibido, en el sentido técnico de la expresión, la enseñanza oficial sobre regulación de la natalidad}

En el tema de la regulación de la natalidad, los fieles se guían por su propia conciencia de creyentes y toman sus decisiones según su situación de vida, discrepando de la enseñanza oficial. Las encuestas de opinión muestran que en su inmensa mayoría los católicos consideran legítimo el uso de los anticonceptivos orales: en Chile, un 95\% de los encuestados (Bentué, 2005). En todo el mundo, incluyendo los países católicos, este y otros métodos anticonceptivos se usan masivamente.

Además, algunas parejas que ya tienen hijos recurren a un método más drástico de regulación de la natalidad: la esterilización quirúrgica. Un estudio realizado en Estados Unidos descubrió que incluso en los hospitales públicos dirigidos por congregaciones religiosas católicas, una significativa parte de ellos, un 20\% (McCormick, 1989), practicaban esterilizaciones quirúrgicas. También en Chile miles de católicos recurren al método quirúrgico, como lo afirma el moralista jesuita José Aldunate:

En la actualidad se practican en Chile más de 13 mil esterilizaciones definitivas al año. El recurso a la píldora y a los dispositivos intrauterinos (DIU) es masivo. Lo es igualmente en la población católica y practicante... Nos preguntamos, pues, si una conducta tan generalizada es necesariamente contraria al espíritu de la ley eclesial. Dios asiste no solamente al Magisterio, sino ante todo al Pueblo de Dios para que no yerre en su caminar... la ley no representa la última palabra. La última palabra la tiene la conciencia. (Aldunate, 2001.)

La no recepción de una doctrina proclamada por más de cuarenta años debe dar que pensar.

\section{Los teólogos morales discrepan mayoritariamente de la enseñanza oficial}

Los especialistas en moral, cuya labor es reflexionar en profundidad sobre los temas religiosos, tomando en cuenta los avances del saber moderno en campos como la medicina, la psicología y la filosofía, ya han evolucionado hacia posturas más afines a la modernidad en el tema de la sexualidad. Pero en el campo de la 
moral sexual le es difícil a la jerarquía acoger la reflexión de sus propios especialistas, los teólogos morales. En 1993 se publicó una encíclica (Veritatis splendor) - algo difícil y técnica- con el fin de regular los límites del disenso en la teología moral, lo que no se ha conseguido. Más aún, la autoridad periódicamente reprocha a algunos de los más destacados moralistas sus propuestas, exigiéndoles que se retracten, lo que llama la atención al tratarse de temas que se refieren a costumbres no centrales en la fe. Algunos teólogos morales han sido enjuiciados, buscando con ello escarmentar a los innovadores.

Bernard Häring, sacerdote alemán, consejero de Pablo VI, es considerado uno de los más grandes teólogos morales de la Iglesia en el siglo XX. Era partidario de una renovación en la moral sexual y fue duramente enjuiciado por Roma durante dos años, siendo finalmente "absuelto" en 1975. Según este autor, actualmente una mayoría de los teólogos morales son disidentes en moral sexual (Häring, 1989).

A Charles Curran, uno de los más respetados teólogos morales norteamericanos se le quitó la autorización de impartir teología moral, debiendo enseñar ahora en universidades cristianas no católicas. En 1968 Curran había encabezado en Estados Unidos la crítica de la encíclica Humanae vitae, afirmando que los matrimonios podían seguir usando métodos anticonceptivos como la píldora, si lo estimaban en conciencia. Redactó una carta disidente que llegó a ser firmada por más de 600 teólogos norteamericanos y europeos.

También en 2001 fue enjuiciado por la Congregación para la Doctrina de la Fe de Roma probablemente el más grande moralista de habla española, el padre Marciano Vidal, autor de importantes libros y formador de generaciones de sacerdotes. Se le reprocharon en especial sus orientaciones innovadoras en materia de moral sexual, como su aceptación moral de métodos anticonceptivos, de algunas formas de fertilización asistida y, en casos de urgencia, de la píldora del día después. También en ciertos casos aceptaba la esterilización. Se le pidió que se comprometiera a "corregir" sus libros, exigencia imposible de realizar en la práctica, al existir hoy millares de ejemplares repartidos por el mundo en decenas de idiomas.

Debemos recordar que también entre nosotros, en Chile, los teólogos discreparon de la Humanae vitae en 1968. "En Chile, un grupo de profesores de la Facultad de Teología escribió directamente al papa haciendo patente que el párrafo 14 se ponía en contradicción con sus conciencias" (Silva Henríquez, 1991).

\section{Muchos sacerdotes discrepan de la enseñanza oficial}

La enseñanza oficial tampoco es compartida por muchos de los pastores que están en continuo contacto con los feligreses y conocen sus problemas cotidianos, pese a que la autoridad ha insistido en pedir obediencia a los sacerdotes. 
En tiempos modernos las personas necesitan comprender la enseñanza, entender sus fundamentos para que puedan hacerla suya de modo interior y voluntario.

Actualmente, pareciera que la mayoría de sacerdotes discrepa de la enseñanza oficial en el tema de la anticoncepción. En el sínodo de obispos de 1980, dedicado al tema de la familia, el obispo Quinn, presidente de la conferencia episcopal estadounidense, pidió cambios en la doctrina moral, informando, entre otras cosas, que en Estados Unidos solo un 29\% de los sacerdotes consideraba que el uso de los anticonceptivos era inmoral (Kaufman, 2004). Y solo una pequeña fracción de los sacerdotes considera que se debe negar la absolución a una mujer que reconozca usar la píldora. En suma, no solo los fieles no consiguen asumir la enseñanza oficial sobre regulación de la natalidad, sino que tampoco lo hacen muchos de los sacerdotes.

Un sacerdote y teólogo de orientación innovadora en este tema, Albino Luciani, llegó a ser papa, Juan Pablo I. Cuando el tema se debatía antes de 1968, Luciani había dado una opinión novedosa, pero después de que Pablo VI tomara una decisión, guardó respetuoso silencio. Más adelante, al inicio de su gestión papal manifestó su intención de abordar nuevamente el tema de la regulación de la natalidad de un modo consultivo y colegial, lo que no alcanzó a realizar (Häring, 1993).

\section{Muchos obispos han pedido un nuevo estudio de la enseñanza en moral matrimonial}

Sobre la anticoncepción. Es sabido que muchas conferencias episcopales matizaron Humanae vitae para calmar la inquietud de muchos laicos que usaban los anticonceptivos. En Chile, los obispos habían aceptado el programa de planificación familiar del Gobierno de Frei Montalvo en los años sesenta. El cardenal Raúl Silva Henríquez recibió una copia de la encíclica antes de ser dada a conocer públicamente. Su primera y meditada reacción, después de hacer consultas, fue enviar al día siguiente al papa Pablo VI, de quien era cercano, un mensaje pidiendo que postergara su publicación (Silva Henríquez, 1991).

Según los obispos holandeses, en el texto de la encíclica Humanae vitae no quedaba fundamentada de modo convincente la norma propuesta.

Treinta obispos de Indonesia declararon que no estaban convencidos por la encíclica, y expresaron que "hubieran preferido que, en una materia tan sensible para la vida de la comunidad cristiana y de todo el género humano, el colegio de los obispos hubiera sido expresamente consultado" (Mahoney, 1987).

Sobre los divorciados vueltos a casar. Otro de los puntos controvertidos en moral es la conducta ante los divorciados que viven en segundo matrimonio. También en esto muchos obispos son partidarios de poner al día la enseñanza de la Iglesia en una orientación flexible y comprensiva. En Francia, monseñor 
Le Bourgeois considera que los segundos matrimonios pueden ser aceptados en la comunión. Tres obispos de Alemania -O. Sauer, K. Lehman, W. Kasper-, entre ellos el presidente de la conferencia episcopal de ese país, escribieron en 1993 una carta pastoral que proponía un discernimiento que eventualmente les permitiera acceder a la comunión (Mifsud, 1995). En Chile, el obispo Hourton y el moralista José Aldunate han escrito en este mismo sentido (J. Hourton, 1994).

Más aún, el tema fue discutido en el Sínodo Mundial de Obispos dedicado al tema de la familia en 1980. Una de las propuestas finales de la asamblea fue solicitar a Roma volver a estudiar el tema de los divorciados y vueltos a casar, tomando como referencia la conducta pastoral de las Iglesias orientales, benévola en este tema (Kaufman, 1994). Pero en Familiaris consortio el papa Juan Pablo II insistió en la doctrina severa de que en los segundos matrimonios los cónyuges debían vivir separados o bien suspender su vida sexual, si deseaban vivir cristianamente. Esto no tiene sentido en el mundo de hoy en el que las nuevas parejas sienten que deben cultivar y cuidar su amor. El pedido mayoritario de los obispos en orden a un reestudio sigue pendiente.

\section{La enseñanza moral sobre la anticoncepción fue decidida en 1968 en contra del consejo de los propios expertos de la Iglesia}

Antes de que el papa resolviera el dilema moral planteado por el descubrimiento de la píldora anticonceptiva, tuvo el buen propósito de pedir asesoría especializada. Juan XXIII formó una comisión para estudiar el tema del crecimiento demográfico en el mundo y los nuevos métodos de regulación de la natalidad. La comisión trabajó durante varios años, y el número de sus integrantes fue ampliado por Pablo VI a cerca de sesenta personas. Participaron especialistas de todo el mundo, demógrafos, economistas, médicos, ginecólogos, psiquiatras, naturalmente todos nombrados por el papa.

También participaron matrimonios, incluyendo mujeres. La integraron 19 teólogos, entre ellos grandes moralistas como Häring, Fuchs, Ford, Auer y otros. También fueron incluidos obispos y cardenales destacados como Suenens y otros, hasta completar 15 altos dignatarios, que se integraron en su jornada final (Buelens, 1969). En 1966, la comisión entregó sus conclusiones al papa de modo reservado, si bien después se hicieron públicas. Recomendaron innovar la doctrina tomando en cuenta tanto la evolución de la tradición religiosa como los nuevos hechos de la modernidad, tales como el crecimiento demográfico, los avances de la medicina, el crecimiento del promedio de vida, los cambios en la familia y los cambios en el rol de la mujer.

Los expertos y pastores recomendaron que fueran los propios esposos quienes decidieran cuál de los métodos se acomodaba mejor a su situación y circunstancias de vida. No especificaban el método, dejándolo al libre discernimiento de los esposos, quienes debían guiarse por ciertos criterios morales, que les eran 
entregados. Los expertos, incluyendo moralistas, obispos y cardenales, decían sí a la regulación de la natalidad. Cuando los esposos lo decidieran con serios motivos, sería legítimo el uso de la píldora, en ese entonces uno de los métodos disponibles.

Pero la resolución final del papa fue exactamente la contraria. El papa solo autorizó el recurso al método de la continencia periódica en los días fértiles de la mujer, ya aceptado antes, y condenó todos los demás, incluyendo la píldora y la esterilización quirúrgica. La autoridad resolvió contra la opinión ilustrada de sus propios especialistas y pastores.

Un desacuerdo tan llamativo muestra que en estos temas aún se estaba en el terreno de lo debatible. Cuál deba ser el mejor modo de resolver este tipo de dilemas morales es un tema a reflexionar. Deben tenerse en cuenta las mejores razones y no solo, de modo exclusivo y determinante, la fuerza de la autoridad, por otra parte legítima. Cuarenta años de una enseñanza que no ha sido "recibida", aceptada, parecen suficientes para abrir un diálogo sincero.

Precisamente con la perspectiva que dan los cuarenta años transcurridos desde la Humanae vitae, el cardenal Martini hace un crítico balance:

Lo más triste es que la encíclica es en parte culpable de que muchos ya no tomen más en serio a la Iglesia como interlocutora o maestra. Pero sobre todo a los jóvenes de nuestros países occidentales ya casi no se les ocurre acudir a representantes de la Iglesia para consultarlos en cuestiones atinentes a la planificación familiar o a la sexualidad... Muchas personas se han alejado de la Iglesia, y la Iglesia se ha alejado de los hombres. Se ha producido un gran perjuicio. (Martini, 2008.)

\section{Las mujeres mayoritariamente han adoptado la regulación de la natalidad}

Humanae vitae, la encíclica que condenó el uso de la píldora, dio como una de sus razones el peligro de que la mujer fuera devaluada a simple objeto de placer para el hombre. Sin embargo, pese a este riesgo, las mujeres de todo el mundo han adoptado en forma masiva los métodos de regulación de la natalidad. Pareciera que la razón ha sido principalmente regular una fecundidad natural que en el pasado muchas veces había sometido a la mujer a una dura carga, en culturas patriarcales tradicionales que reservaban al hombre la libertad en su conducta personal. En América Latina, sabemos por experiencia que hasta mediados del siglo XX muchas familias de conducta tradicional tenían típicamente una docena de hijos o más, en familias terratenientes o en familias pobres, campesinas. El cardenal chileno que participó en el concilio, Raúl Silva Henríquez, venía de una familia de 19 hijos. 
Pues bien, muchos factores sociales y económicos han llevado a un cambio en estas pautas de fecundidad conyugal. En todo el mundo, las mujeres han percibido que los modernos métodos de regulación de la natalidad les permiten enfrentar su vida matrimonial de modo más libre y autónomo. Pueden postergar y programar su maternidad de modo razonable, en vez de dejarlo al azar. La mujer ha descubierto su derecho a un proyecto personal propio, en el mundo laboral y social, independiente de su rol maternal.

En Chile, en los años sesenta, el promedio de hijos por mujer era cerca de cinco. En 2000 ha caído a dos. En un estudio realizado para el diario Le Monde en 1988 en Francia, se les preguntó a mujeres su opinión sobre acontecimientos fundamentales del siglo XX, poniendo ellas en primer lugar la píldora anticonceptiva antes que el teléfono celular y los computadores. Investigaciones calculan que en el mundo hay aproximadamente 428 millones de mujeres que usan métodos anticonceptivos considerados en general. De este número, la mayor proporción corresponde a los métodos quirúrgicos (207 millones), seguidos por los dispositivos intrauterinos (125 millones) y luego los fármacos hormonales (96 millones) (Heritier, 1999). Todos estos métodos son moralmente condenados por la jerarquía católica. (Dejamos fuera de esta reflexión la anticoncepción de emergencia, o píldora del día después, técnicamente más compleja.)

Debemos destacar que en la Comisión Pontificia de Estudios que asesoró al papa entre 1964 y 1966 sobre el tema del control de la natalidad participaban cinco mujeres casadas. Su experiencia y testimonio unánime fue muy importante para persuadir a los teólogos y sacerdotes de la comisión de que era necesario avanzar a posturas innovadoras en el tema de la regulación de la natalidad, sin restringirse solo al método natural, que no era adecuado para muchas mujeres y parejas. Ellas fueron escuchadas al interior de la comisión, pero el papa rechazó las conclusiones. La posición de esas mujeres invitadas por el papa resultó premonitoria sobre cuál sería en el futuro la posición de las mujeres en el mundo entero, fueran o no creyentes. Esta actitud decididamente innovadora de las mujeres debe dar que pensar a una Iglesia dominada por varones en sus posiciones de poder.

Por su parte, la jerarquía sigue confiando en un solo método de regulación de la natalidad, el denominado método natural, de continencia periódica en los días fértiles de la mujer. Nos parece revelador que en el Sínodo Mundial de Obispos de 1980, dedicado al tema de la familia, la autoridad romana invitó a dar conferencias a expertos en el método natural, encabezados por el propio Dr. Billings. Además, invitó en lugar destacado a una madre de 17 hijos (Blair Kaiser, 1985). Estos son signos de adhesión a una visión tradicional de la sexualidad y la familia, que se ha distanciado de la sensibilidad moderna. Por contraste, como veremos, hoy muchas voces proponen que la Iglesia debe dar orientaciones en moral sexual y no comprometerse con soluciones especificas, las que deben ser dejadas al discernimiento de los fieles. 


\section{Aceptación de los fieles de la fertilización asistida pese al rechazo oficial}

En el siglo XX se ha podido conocer mejor la fisiología de la procreación humana. Esto ha permitido ayudar a millares de parejas que no podían tener hijos biológicos. Para la mayoría de personas esto parece ser un notable progreso, que usado responsablemente puede mitigar mucho dolor y traer satisfacción a matrimonios que pueden completar su familia con hijos queridos y esperados. Se estima que en el mundo han nacido cinco millones de niños por estos métodos. Muchos fieles se abren a reflexionar sobre estas nuevas realidades. Sin embargo, la jerarquía católica insiste en condenar la mayoría de los métodos modernos de fecundación artificial. En este tema la mayoría de teólogos morales considera que muchos de los nuevos métodos son moralmente legítimos, especialmente en los casos en que la fecundación se logra con el óvulo y el semen de los esposos.

El fundamento para rechazar estos métodos por la enseñanza oficial es cierto principio moral: no puede separarse la concepción de un ser humano de la relación sexual conyugal. Este principio fue enunciado en Humanae vitae: "La inseparable conexión que Dios ha querido... entre los dos significados del acto conyugal: el significado unitivo y el significado procreador". Sin embargo, no se ha podido fundamentar ni demostrar esta supuesta unión indisoluble entre los dos significados. Por el contrario, estos significados los separa espontáneamente la propia naturaleza en cada ciclo femenino, que tiene días fértiles seguidos por días infértiles. La visión moral innovadora propone, en cambio, que solo el conjunto de la vida conyugal debe estar abierta a la fecundidad (por tanto, considera que la fecundidad no es necesaria en "cada acto"). En la fertilización asistida, la procreación suele conseguirse separada de la unión sexual. El magisterio insiste en condenas que no logra justificar ante la razón moderna. Parece haber aquí una obediencia a conceptos antiguos y se rechaza hasta ahora repensarlos con el fin de adaptarlos mejor a los nuevos tiempos.

La ciencia médica ha hecho notables avances en el conocimiento y el dominio de la fecundidad humana, la que fue hasta hace poco una fuerza exuberante y misteriosa. Hoy es posible gobernar esta función biológica ya sea frenándola, en el caso de la anticoncepción, o bien estimulándola, en el caso de la fertilización asistida. Ambos avances parecen no haber sido incomprendidos hasta hoy por la enseñanza oficial, que los condena de modo global.

\section{Una teología moral de raíces en la Antigüedad es insuficiente en la modernidad}

Muchas posturas de la jerarquía en la moral sexual se explican por adherirse a ideas religiosas construidas en la Antigüedad, en sociedades tradicionales de tipo agrario y feudal. Sin embargo, en comparación con la Iglesia primitiva, la cultura bíblica anterior era mucho más libre -y podría decirse "moderna"- en temas sexuales. El Antiguo Testamento contiene muchos textos que ensalzan el 
deseo y el placer sexual como algo bueno y querido por Dios, como el Cantar de los Cantares. Según Schökel, en Isaías se encuentra una de las imágenes más audaces sobre el amor de Dios con su pueblo. El gozo del marido con la esposa es atribuido al Señor: "Como un joven se casa con una doncella / así te desposa el que te construyó / la alegría que encuentra el marido con su esposa / la encontrará tu Dios contigo" (Is 62) (Schökel, 1997). El encuentro de los jóvenes esposos es digno de ser figura del amor divino: no hay mayor privilegio para una experiencia humana. El Nuevo Testamento también abunda en imágenes nupciales: "El Reino de Dios se parece a un rey que celebra la boda de su hijo"; y también: "Entonces, el reinado de Dios será como diez muchachas que salieron con sus candiles a esperar al novio" (Mt 22 y 25).

Ni en el Nuevo ni el Antiguo Testamento se afirma que la procreación sea el fin esencial de la sexualidad, como después afirmará la tradición durante mil años. Pensamos que la moral innovadora moderna en cierta forma solo retorna a una moral de inspiración más bíblica. La idea de que el fin principal del matrimonio y la sexualidad es tener hijos llega a la Iglesia primitiva desde la cultura latina y helénica, siendo luego adoptada como propia por la Iglesia antigua. Esta influencia cultural llevó a una visión pesimista y negativa de la sexualidad, reforzada por autores como Agustín de Hipona, quien llegó a referirse al placer sexual como "el regalo del demonio" (Brown, 1988).

En el Imperio romano la expectativa de vida era de 25 años. Muchas mujeres casadas morían antes de esa edad. Muy pocas personas sobrepasaban la edad de los cuarenta. Era natural que en estas sociedades se ensalzara la fecundidad como un máximo valor, por una cuestión de sobrevivencia. Esta realidad afectó la teología de su época, que privilegió la fecundidad en el matrimonio. Esto explica una cierta sacralización de la fecundidad matrimonial, lo que en la modernidad ya se ha hecho anacrónico.

Esta teología clásica es inadecuada en nuestra época, en que las personas viven hasta los ochenta años, y pocas veces quedan viudos jóvenes, lo que era común antes. Recordemos que en la modernidad se redescubrió la importancia de la alianza del amor entre los esposos. El matrimonio ya no es un deber para perpetuar la vida social, como era antes. El matrimonio también debe dar vida y enriquecimiento a los propios esposos, y parte significativa es su intimidad sexual y afectiva. Esto fue reconocido en el último concilio al quedar atrás el modelo jurídico del matrimonio y preferir un enfoque personalista, de alianza y comunidad de vida y amor.

Recién en el siglo XX se descubrió el primer método de regulación de la natalidad, que fue el método del ritmo o continencia periódica en los días fecundos de la mujer (posteriormente mejorado en el Billings). Este primer método cambió la relación de los esposos con su sexualidad y modificó de modo radical la cultura en este asunto. Los esposos descubrieron la posibilidad 
de cultivar su vida sexual por el placer de sí misma, sin buscar la procreación. Esto fue una revolución cultural que permitió el aprendizaje de una regulación legítima de la natalidad, experiencia que probablemente preparó a la mayoría de los esposos católicos para aceptar luego el segundo gran descubrimiento en este tema: la píldora anticonceptiva.

Todas estas novedades surgidas por la evolución social y por la ciencia moderna deben ser pensadas con nuevos conceptos teológicos, apropiados a la modernidad. No pueden juzgarse las modernas técnicas médicas de anticoncepción y fertilización asistida a partir de una teología clásica, que desconfiaba de los fármacos como si fueran cosa de hechiceros, como ocurría en la Antigüedad.

Con respecto a la generación humana, la moral clásica conserva una visión de la naturaleza que la deja en una suerte de espacio sagrado, como expresando directamente la voluntad de Dios: respetar a Dios sería sinónimo de respetar la naturaleza. Así lo pensaba el entonces cardenal Ratzinger, cuando afirmaba: "Para la Iglesia el lenguaje de la naturaleza (...) es también el lenguaje de la moral (...) Es en nombre de la naturaleza (...) que la Iglesia eleva su voz contra la tentación de predeterminar las personas y su destino (...) Respetar la biología es respetar a Dios mismo y, en consecuencia, respetar sus criaturas" (J. Ratzinger, "Entrevista sobre la fe", citado en Duquoc, 1988). Esta idea, que corresponde a una teología clásica, de que respetar la biología es respetar a Dios, ya no es convincente para el hombre de hoy. El teólogo Christian Duquoc muestra la insuficiencia de los fundamentos de la moral sexual católica desde una perspectiva dogmática.

Vemos cómo en la moral clásica se concibe a la naturaleza expresando el orden moral divino. Esto es semejante a cómo en la Edad Media se condenaban ciertos actos como malos por contradecir a la naturaleza. En la condena actual de las técnicas modernas, como la anticoncepción y la fertilización asistida, subyace la idea de que es pecaminoso ir contra natura, lo que expresa una teología incomprensible en la modernidad. Pues forma parte de la naturaleza humana el desarrollo de la técnica para transformar el mundo, y la técnica es normalmente ir contra natura, como bien lo sabemos los médicos.

Hoy día contamos con criterios más integrales para discernir lo moralmente bueno, diferentes de la mera conformidad con lo natural. En verdad lo malo no es lo que va contra la naturaleza, sino lo que va contra el desarrollo humano del mundo. Buena parte de la terapéutica médica contraría la naturaleza, buscando dominarla para hacer el bien a favor de la salud. Si algo parece contrario a la naturaleza pero sirve al amor y la vida, es bueno. Así lo declaraba el concilio: "De ahí que la norma de la humana actividad es la siguiente: que según el designio y voluntad divina, responda al auténtico bien del género humano" (Gaudium et spes 35). 


\section{El pensamiento conservador teme a la ciencia y debe renovarse}

El pensamiento tradicional se adhiere al modelo conocido del mundo y desconfía de cualquier novedad viendo, equivocadamente, un peligro para la fe. Efectivamente, las novedades producen crisis culturales en cada época, pero estos son procesos necesarios y llevan gradualmente a un progreso.

En la Edad Media se persiguió a personas juzgadas como brujas, muchas de las cuales eran mujeres mayores que acompañaban a las madres en sus partos, siendo conocedoras de hierbas y herederas de un saber tradicional sobre la salud. Más tarde, cuando el médico inglés Jenner descubrió la vacuna fue incomprendido: su invento fue condenado por un papa y prohibido en Roma en 1829, considerando la vacuna una ofensa contra Dios, pues alteraba el orden natural en que la enfermedad de la viruela era vista como una prueba para el hombre (González Faus, 2006).

Cuando la reina Victoria usó por primera vez la anestesia en un parto, se cuestionó a su médico, considerándose que contradecía el mandato bíblico de "parirás tus hijos con dolor" (Ranke-Heinemann, 1994). Durante décadas se condenó la incineración de cadáveres, excluyéndose en los funerales católicos, por temores relacionados con la idea de la resurrección. Los trasplantes de órganos fueron resistidos inicialmente. Hasta el día de hoy la autoridad católica prohíbe recurrir a la masturbación con el objeto de conseguir una muestra de semen para un examen médico, ya sea un estudio de esterilidad o bien para decidir un tratamiento infeccioso.

Fuera de la medicina también el pensamiento religioso conservador ha sido temeroso. Además del caso de Galileo, se rechazó la teoría de la evolución de Darwin, temiéndose que cuestionara la idea de creación del hombre. En tiempos de Felipe II, fueron rechazadas las primeras canalizaciones de ríos de Europa, pues se creía que el orden natural dado era el querido por Dios y que sería una ofensa modificarlo (Schillebeeckx, 1970). La invención del ferrocarril fue inicialmente condenada por un papa (Robinson, 2008).

Ha sido frecuente la resistencia a lo nuevo de la ciencia, desde el temor y la defensa de lo conocido. Vemos la resistencia actual del magisterio frente a la anticoncepción y otros descubrimientos sobre procreación humana como un caso más de incomprensión de la ciencia y de lo nuevo por parte del pensamiento religioso tradicional. Sin embargo, muchos moralistas innovadores y fieles perciben que mucho de lo nuevo es valioso y completamente compatible con la fe religiosa.

\section{Otras iglesias cristianas se han renovado en temas de moral sexual}

La Iglesia católica insiste en ciertas normas morales que las demás iglesias cristianas ya abandonaron. La Iglesia anglicana aceptó la regulación de la 
natalidad ya en 1930, siguiendo luego las demás iglesias protestantes. Pero la Iglesia católica insiste en mantener una norma heredada de siglos anteriores como la única doctrina cristiana auténtica.

La posición católica oficial - la del Vaticano- en las jornadas de estudio internacionales ha ido quedando alarmantemente aislada. En algunos congresos internacionales la postura romana tradicional en sexualidad solo es compartida por países islámicos muy tradicionalistas. Nos preguntamos si la conservación de ciertas posturas morales como el rechazo de la anticoncepción pueda deberse a una actitud cultural más que a una verdad religiosa auténtica.

Es útil recordar que en otro tema religioso muy importante, las iglesias protestantes acertaron en el siglo XIX, antes que los católicos. Durante años la jerarquía católica rechazó los métodos de exégesis histórico-críticos, cuando se empezaron a utilizar en la lectura e interpretación de la Biblia. Este era un aporte de la ciencia moderna, en especial de la ciencia histórica. La Iglesia católica rechazó el uso de estos nuevos métodos que permitían aplicar a la Biblia el concepto de los géneros literarios y muchos otros, lo cual enriquecía la comprensión de la Escritura. La condena del nuevo método de exégesis fue un error semejante a la condena del fundador de la ciencia moderna, Galileo. Sabios como el padre Lagrange fueron condenados a no publicar. Finalmente, estos métodos comenzaron a ser aceptados por Pío XII en 1943. A partir de ahí, la Iglesia católica pudo aprender de la Iglesia protestante sobre los nuevos métodos de exégesis (Schökel, 1959).

Quizás en temas de moral sexual los católicos podamos aprender de las demás iglesias cristianas, las que en ocasiones han captado antes los aportes de la modernidad. Si en el tema del segundo matrimonio la iglesia oriental tiene una práctica benévola, ¿por qué no podríamos los católicos aprender de estos hermanos en la fe?

\section{Es normal que en la historia, el magisterio se ha equivocado en temas no centrales a la fe}

La autoridad católica puede equivocarse en temas sujetos al desarrollo del saber y de la historia, lo que ha ocurrido numerosas veces, pues está compuesta por personas falibles inmersas en la historia. La Iglesia legitimó por siglos la tortura como procedimiento judicial. Solo hace poco captó que era inaceptable e inhumana. Se trató de un progreso de la cultura, más que de la fe religiosa. Algo semejante ocurrió con la esclavitud, aceptada por siglos por el magisterio junto a la cultura de la época.

En la vida económica, durante varios siglos, la Iglesia condenó el cobro del interés del dinero como pecado de usura. Posteriormente la Iglesia debió poner al día su visión en este tema, gracias a las propuestas de personas - sacerdotes 
y laicos - con conocimientos administrativos y financieros. Otros avances culturales también fueron incomprendidos por la Iglesia inicialmente, rechazándose la libertad de prensa y la democracia. En el siglo XIX, la naciente independencia de América fue incomprendida y rechazada inicialmente por Roma (Krebs, 2002).

Es normal que una institución de dos mil años pueda errar en temas contingentes, influidos por la cultura y la historia. Pero también es normal que los errores gradualmente se corrijan en diálogo con la cultura en la cual está inmersa, y así ha ocurrido en el pasado. Por eso, en estos temas de sexualidad la Iglesia debe actualizase en diálogo con la cultura de hoy.

\section{La pedofilia y la credibilidad moral de la Iglesia}

El escándalo de los casos de abuso sexual de menores perpetrados por sacerdotes en todas partes del mundo ha afectado seriamente la credibilidad de la institución. Muchas personas se han visto decepcionadas por lo que consideran un manejo lamentable de las autoridades religiosas en la investigación y el tratamiento de este problema. Una Iglesia que ha sido tan exigente con los laicos en materia de moral sexual, descubría ahora que ha sido débil con los sacerdotes abusadores.

El caso Maciel resultó conmovedor en todo el mundo. En todas partes aparecieron otros casos, quizá escasos en número, pero significativos por su prestigio y notoriedad. Entre 1990 y 2003 han debido renunciar 21 obispos de diez países, debido a conductas sexuales impropias de ellos o bien por su mal manejo de la conducta sexual inapropiada de otros sacerdotes (Gail, 2008). Posiblemente el celibato por sí mismo no es un factor determinante en el origen de los abusos, pues este mal lo sufren también instituciones e iglesias cuyas autoridades no son célibes. Pero también es posible pensar que si en la Iglesia católica hubiera un número significativo de sacerdotes casados y con hijos probablemente se habría reaccionado de manera más pronta y adecuada. Los temas sexuales se ventilarían de otra manera en una institución donde sea normal casarse y tener vida sexual también en el sacerdocio. Son interrogantes que pueden ser planteadas.

La crisis de la pedofilia en la Iglesia está en curso y no ha terminado. Muchas personas han sentido razonablemente que la institución debería repensar de modo más general el tema de la sexualidad, la moral y la disciplina en toda la institución. Si ha habido insuficiencias en el abordaje de la sexualidad de los sacerdotes, ¿no las habrá también en el abordaje de la sexualidad de los laicos? 


\section{Un posible camino en la puesta al día de la moral sexual: la moral social ya se ha la renovado}

El notable desarrollo de la doctrina social de la Iglesia desde hace cien años, desde León XIII en adelante, ha hecho progresar la enseñanza social en diálogo y en fecundación mutua con las ciencias humanas modernas. La rica reflexión religiosa en temas cruciales como el trabajo, los derechos humanos, la pobreza y la justicia social, la paz y la violencia en el mundo, han puesto a la Iglesia en un sitial destacado como maestra en temas de moral social, siendo respetada mundialmente, si bien no siempre sean acogidas sus enseñanzas como sería de desear. ¿Cómo fue posible esta renovación en la enseñanza?

Aquí ha sucedido una evolución imperceptible pero sustantiva: la Iglesia ha renovado el método y la epistemología de su enseñanza social. Vimos cómo en el pasado la Iglesia debió corregir sus directrices en temas concretos como el interés del dinero, la esclavitud y la tortura, aprendiendo junto a la cultura de su época. Pues bien, a partir de esas experiencias la autoridad ha aprendido a renunciar a dictar normas específicas en moral social. La Iglesia ya practica un nuevo método en moral social, como se observa en Octogesima adveniens y en el catecismo. En su enseñanza actual la Iglesia ha decidido entregar "principios de reflexión", "criterios de juicio" morales, y también "orientaciones para la acción" que señalan una clara dirección moral, pero permiten que los propios ciudadanos y las fuerzas sociales disciernan las soluciones específicas en el ámbito político, económico y social (Calvez, 1993).

Muchas voces autorizadas reclaman que la Iglesia - aprendiendo de su propia experiencia en lo social- adopte también ese método y elabore una nueva formulación de la moral sexual. De esta manera, la enseñanza en moral sexual, en vez de seguir adherida a la costumbre de prohibiciones múltiples y detalladas, podría en el futuro renunciar a dictar las normas específicas y señalar, en cambio, una orientación moral clara, pero dejando a los fieles el espacio de discernimiento para decidir como adultos con conciencia formada, las acciones específicas en su situación de vida y circunstancias.

Desde una perspectiva dogmática, Duquoc ha mostrado que el espacio de discernimiento que la enseñanza social de la Iglesia entrega en relación a la sociedad y al Estado debe extenderse al ámbito de la familia y la sexualidad (Duquoc, 1988). Según este autor, no puede justificarse dogmáticamente esta flagrante discrepancia entre la amplia libertad confiada al hombre en lo social y la estrecha restricción de su libertad en lo sexual. No puede justificarse teológicamente lo que hoy ocurre: el hombre participa libremente en completar la creación divina en el espacio de la sociedad, la economía y la política, pero en el espacio familiar y sexual debe limitarse dócilmente a obedecer normas presuntamente escritas en la naturaleza. También el teólogo social Ives Calvez ha señalado que 
una puesta al día de la moral sexual debería seguir el camino ya aprendido por la Iglesia en la moral social.

En este mismo sentido se expresó el obispo Ernst, de Breda, Holanda, en el Sínodo de la Familia de 1980:

¿No podrá ser deseable que el magisterio proponga su enseñanza moral sobre matrimonio y familia del mismo modo que lo hace con la doctrina social, a saber, mostrándose reservado, en la medida de lo posible, en las aplicaciones concretas y ayudando a los cristianos a encontrar la verdad moral concreta por medio del examen de la realidad a la luz del Evangelio y de la enseñanza de la Iglesia? (Ernst, 1980, en Elizari, 1981.)

En conclusión, cada día hay más razones para pensar que la Iglesia católica debe dar paso a un diálogo y una puesta al día de su pensamiento en moral y sexualidad. Las normas oficiales ya no son entendidas ni compartidas por los propios fieles, ni por muchos sacerdotes y teólogos. La cultura moderna se vuelve crecientemente escéptica sobre la palabra de la Iglesia en el terreno de la sexualidad.

Vimos cómo en el pasado muchos avances de la ciencia en general y de la medicina en particular, que fueron incomprendidos inicialmente por el pensamiento religioso tradicional, fueron luego comprendiéndose mejor, siendo tamizados y en parte integrados al saber común. Una fe religiosa con vocación universal debe insertarse en la cultura en la que está inmersa y dialogar con ella. Así ha ocurrido siempre con la fe católica. Nacida en cuna judía, los padres antiguos pensaron luego su fe en los conceptos de la cultura griega. Después, la Iglesia aprendió de la cultura romana el concepto de ley y organización. En la Edad Media, Tomás de Aquino fue capaz de armonizar su fe con la recién descubierta filosofía de Aristóteles.

En el siglo XX, el Concilio Vaticano II fue capaz de grandes innovaciones para poner al día la fe católica en el mundo moderno. El concilio hizo reformas extraordinarias, entre las que podemos destacar las litúrgicas, con la aceptación del lenguaje vivo del pueblo; los avances en exégesis; y en la libertad religiosa. Pero el pensamiento sobre sexualidad está quedando rezagado y en conflicto con las nuevas maneras de concebirla y vivirla, propias de estos tiempos. La enseñanza en moral sexual, en vez de desarrollarse, ha quedado adherida a normas y prohibiciones que tuvieron algún sentido en el pasado.

Es posible y normal equivocarse al formular una enseñanza. Pero no es adecuado perseverar en una doctrina que hoy resulta insuficiente por incapacidad de corregir o por pensar que una corrección debilita la autoridad religiosa. Por el contrario, la autoridad ya se ha debilitado precisamente por sus fallos en el tema y ahora se trata de recuperar la credibilidad en un diálogo y una búsqueda común. Hace poco un testigo autorizado como el cardenal Martini decía, a propósito de la moral matrimonial: 
Casi cuarenta años de distancia (desde Humanae vitae) - un tiempo tan prolongado como la marcha de Israel por el desierto- podrían permitirnos una nueva perspectiva... Estoy firmemente convencido de que la conducción de la Iglesia puede mostrar un camino mejor del que logró mostrar la encíclica Humanae vitae. La Iglesia recuperará con ello credibilidad y competencia. (C. M. Martini, 2008.)

En la situación moral actual, es más necesario que nunca resaltar la auténtica riqueza de los valores cristianos aportados por la milenaria tradición moral católica: el valor de la vida, la dignidad de la persona, la belleza y dignidad de la pareja humana, la nobleza del amor sexual conyugal, el don divino de los hijos, la belleza del compromiso y fidelidad de por vida. Estos son grandes valores de siempre que lamentablemente hoy a los ojos del mundo están velados por nuestras propias insuficiencias y por una formulación moral legalista y disciplinaria.

Es necesario que el mundo católico, como conjunto, sea capaz de elaborar una moral sexual moderna y realmente orientadora en el ámbito de la sexualidad, que sea en verdad una buena noticia para hombres y mujeres de hoy en búsqueda, quienes en estos temas necesitan sentir más cercanos a sus pastores.

\section{Referencias bibliográficas}

A. Bentué, La "opinión" de las mayorías en la Iglesia. Su valor teológico, mensaje n. ${ }^{\circ}$ 545, diciembre 2005.

A. Valsechi, Regulación de los nacimientos. Diez años de reflexión teológica, Sígueme, Salamanca, 1968.

B. Häring, "Una desconfianza que hiere. Comentario a Veritatis splendor", The Tablet, octubre 1993. Disponible en http://servisioskoinonia.org/relat/

B. Häring, Mi experiencia en la Iglesia, PS Editorial, Madrid, 1990.

C. Duquoc, Procreation et dogme de la creation, Lumiere et Vie, t. XXXVIII, n. ${ }^{\circ}$ 187, julio 1988.

C. M. Martini, Coloquios nocturnos en Jerusalén, San Pablo, Madrid, 2008.

Congregación para la Doctrina de la Fe, Notificación sobre algunos escritos del Rvdo. P. Marciano Vidal, Roma, 2001.

E. Schillebeeckx, El mundo y la Iglesia, Sígueme, Salamanca, 1970.

F. Héritier, Masculino/Femenino, II, Fondo de Cultura Económica, Buenos Aires, 2007.

F. J. Elizari (ed.), El sínodo de la familia. Selección de intervenciones de los obispos, Paulinas, Madrid, 1981.

G. Robinson, Poder y sexualidad en la Iglesia, Sal Terrae, Santander, 2008. 
H. y L. Buelens-Gijsen, Matrimonio católico y anticoncepción, Península, Barcelona, 1969.

J. Aldunate, Una voz que empuja nuestra historia, Mosquito, Santiago, 2004.

J. Hourton, Sexualidad, familia, divorcio, San Pablo, Santiago, 1994.

J. I. Calvez, Morale sociale et morale sexuelle, Études n. ${ }^{\circ}$ 378, mayo 1993.

J. I. González Faus, La autoridad de la verdad. Momentos oscuros del magisterio eclesiástico, Sal Terrae, Santander, 2006.

J. Mahoney, The Making of Moral Theology, Oxford University Press, Nueva York, 1987.

J. Ratzinger y V. Messori, Informe sobre la fe, B. de Autores Cristianos, Madrid, 1980.

L. A. Schökel, El hombre de hoy ante la Biblia, Editorial Juan Flors, Barcelona, 1959.

L. A. Schökel, Símbolos matrimoniales en la Biblia, Editorial Verbo Divino, Burgos, 1997.

M. G. Frawley-O’Dea, La perversión del poder. Abuso sexual dentro de la Iglesia católica, Lectorum, México D. F., 2008.

O. Sauer, K. Lehman y W. Kasper, "Principios para el acompañamiento pastoral de personas cuyo matrimonio ha fracasado, o separadas y vueltas a casar", 10 de julio de 1993; en T. Mifsud, Divorcio, preguntas y respuestas, San Pablo, Santiago, 1995.

P. Brown, The Body and Society. Men, Women and Sexual Renunciation in Early Cristianity, Columbia University Press, Nueva York, 1988.

P. Kaufman, Manual para católicos disconformes, Marea, Buenos Aires, 2004.

R. Blair Kaiser, The Politics of Sex and Religion, Leaven Press, Kansas, 1985.

R. Krebs, La Iglesia en América Latina en el siglo XIX, Editorial Universidad Católica de Chile, Santiago, 2002.

R. McCormick, The Critical Calling, Georgetown University Press, Washington D. C., 1989.

R. S. Henríquez y A. Cavallo, Memorias, Ediciones Copygraph, Santiago, 1991.

U. Ranke-Heineman, Eunucos por el reino de los cielos. Historia de la sexualidad en la Iglesia católica, Trotta, Madrid, 1994. 